\title{
AN ANALYSIS OF INTER-DISTRICT VARIATION IN HEALTH STATUS OF ODISHA WITH A SPECIAL REFERENCE TO HEALTHCARE
}

\author{
Ashok Bhukta \\ Ph.D. Scholar, Department of Economics, Berhampur University \\ Prof. Sudhakar Patra \\ Professor, Department of Economics, Berhampur University
}

Article DOI: https://doi.org/10.36713/epra6904 DOI No: 10.36713/epra6904

\begin{abstract}
The objective of this present study is to the analysis of inter-district variation in the health status of Odisha with a special reference to Healthcare. Health is an important view of health care. One needs good health to lead an economical life. The health of individuals and communities depends upon various socio-economic, demographic and environmental components. To understand the situation of health care an analysis of indicators such as infant mortality rate, death rate, birth rate, life expectancy, Sex ratio, Doctor per thousand of population, medical in hospital per thousand of population, Beds per thousand of population, and literacy rate have been employed through various quantitative techniques like composite index, Descriptive Statistics, Correlation etc. The study depends entirely on secondary data. The relevant secondary data have been collected from various dependable sources. Although the level of health status in Odisha has shown substantial improvement over the years, yet there are marked inter-district variations in health achievements of the Odisha and their districts are at a deplorably low level of health status.

In this context, the main aim of this objective is to an analysis of Inter-District Variation in Health Status of Odisha with a special reference to Health care with Annual Health Survey (2012-13) presents data and methodology.
\end{abstract}

KEY WORDS: Birth Rate, Death Rate, Infant Mortality, Life Expectancy, Sex Ratio, Literacy Rate, Growth Rate

\section{INTRODUCTION}

In this article, an attempt has been made to analyse the findings of various health studies that have been carried out at the national and regional level. Including a comparative analysis between Odisha and districts, an effort has been made to bring out the health inequities by districts, by castes groups, by education, by wealth quintiles, by age groups, etc within the state. Various health indicators that have been included for analysis are the Human Development Index (HDI) vs. Health Index; life expectancy, curd birth rates, curd death rates, infant mortality rates; health care status etc. "Health is wealth" goes the adage in India and it is relevant for all countries of the world. Health is a holistic and multidimensional phenomenon. It is an important aspect of human well being. One should keep one body and mind fit and active to enjoy life and contribute to the good of society. The World Health 


\section{SJIF Impact Factor 2021: 8.013| ISI I.F.Value:1.241| Journal DOI: 10.36713/epra2016 ISSN: 2455-7838(Online) EPRA International Journal of Research and Development (IJRD) Volume: 6 | Issue: 4 | April 2021 \\ - Peer Reviewed Journal}

Organisation (WHO) defines health "as a state of complete physical, mental and social well being and not merely criteria such as life expectancy, work capacity, need for medical care, or ability to perform a variety of personal and social functions. It may also be defined in terms of life expectancy at birth (LEB), the infant mortality rate (IMR), the crude death rate (CDR) or in a self-evaluation of health status or simultaneous account of mortality, morbidity or disability or in terms of disability-adjusted life years (DALY) or terms of quality-adjusted life years (QALY). Therefore it varies with the purpose on hand and the meaning of health one takes into account.

Health is one of the basic indicators of development. People must be healthy and active to participate in different developmental programmes. The importance of the public sector in health needs no belabouring, given the proportion of poverty in the developing countries. The World Bank have played an increasingly significant role in changing the pattern of investments and production in health and associated sectors, depending on priorities regarding where and how the money is to be spent. A healthy individual is an asset to a community while a sick person is a liability. In India, a large infrastructure exists for providing health care services. But the facilities are not properly utilized because of various reasons (Tekhre, Y.L., Tiwari, V. K. \& Khan, A. M., 2004).

Society's health is influenced by the accessibility, affordability, quality, availability and utilization of health services. The best health services are those that are easily accessible, both time-wise and distance-wise to all classes of society, and those that can be afforded by society. It is the government which provides them, making it affordable to the people who utilize them, in a minimum acceptable standard keeping in view the need of the users at each level (NSSO, 2004).

The dependence on government health services is diminishing despite higher costs of private sector services. Why is this so? One reason is the lack of adequate infrastructure and personnel at public health care facilities. The second reason is the poor quality of service of the government's health care units. Therefore, the private sector has had a growing share in various sub-markets such as medical technology, diagnostics, curative health care pharmaceuticals, hospital construction, ancillary services and curative health services. It is estimated to provide $81 \%$ of outpatient care and $46 \%$ of inpatient care in India. $68 \%$ of India's 16,000 hospitals and 37\% of its 60, 00,000 beds are in the private sector (Ghosh, P. K., 2008).
When it comes to health status and health care, Indians are split into two groups - the first comprising of the middle and upper classes of urban India with access to quality medical care. However, the second and larger group comprised of those that live below the poverty line in rural areas and have limited access to medical care. The successive rounds of the (Jalandhar, P. \& Arokiasamy, P., 2006) National Family Health Survey (NFHS 1-3) revealed huge ruralurban differences in key maternal and child health indicators. Rural people also spend less on health care as compared to their urban counterparts. The inequalities in the distribution of selected sensitive measures of health status: infant mortality rate (IMR), under-five mortality rate and life expectancy at birth (LEB) have been interpolated. The 2011 Census reveals that more than 70 per cent of the households of rural India do not have toilet facilities. Unsafe and unhygienic birth practices, unclean water, poor nutrition, poor habitats, and unsanitary environments are challenges to the public health system (Goli, S. 2012).

To improve the prevailing situation, the Government of Odisha launched the National Rural Health Mission (NRHM) programme through the state. It becomes necessary to assess the impact of NRHM on the health infrastructure and the health indicators and to analyze the determinants of health status in the healthy development of Odisha. The study shows that the health status of the study area is very poor and is gradually increasing as a result of the implementation of NRHM and the staple reasons for this tendency are: low income, illiteracy, shortage of doctors, unwillingness doctors to go to remote areas and lack of health care facilities (Patra, S. K., 2013).

The main objective of this article is to examine the nature of the health status of Odisha and its various districts in rural-urban variation. Health status is multidimensional and difficult to measure precisely. It is captured through a range of indicators. Life expectancy at birth, Crude Birth Rate, Infant mortality rate, Doctors per ' 000 of population, Hospitals per ' 000 of population, Beds per ' 000 of population, Literacy Rate, Sex Ratio, and Crude Death Rate are the noted variables on which data have been collected and examined from 2012-13. Further, growth rates have been computed and analyzed (Mishra, P. \& Agarwal, A., 2017). To look into Inter-district variation, descriptive statistics, rank correlation and coefficient of variation has been calculated and interpreted accordingly. Growth Rates to be Calculate in Annual growth rates were computed for respective 


\section{SJIF Impact Factor 2021: 8.013| ISI I.F.Value:1.241| Journal DOI: 10.36713/epra2016 ISSN: 2455-7838(Online) EPRA International Journal of Research and Development (IJRD) Volume: 6 | Issue: 4 | April 2021 \\ - Peer Reviewed Journal}

states over the period. In this analysis, annual growth rates were calculated in the case of public health expenditure and further growth rates were calculated in the case of examining the health status.

\section{Hypothesis}

In this objective of the process of data collection and review of literature, a certain hypothesis was formulated. The main factor responsible for the poor health care condition in Odisha. Above mentioned objective, the present study proposes the following hypothesise:

\section{METHODOLOGY}

Methodological difference between the size of the population and area of 30 districts has been shown in this study. Annual Health Survey data based on population/area, in ratio and percentages, are more suitable to estimate the magnitude of inter-district disparities in public health. Following techniques were applied to analyze the data for achieving the desired objective. These techniques are discussed below: In this article, the aim to analyse the inter-state disparities in the health sector in 30 districts in Odisha selected based on population. The researchers have selected only 15 states because these selected states alone account for about 90 per cent of the total population in Odisha is sufficient to represent the inter-district's variations in the state. This is attempted through a comparative analysis of various parameters depicting health expenditure, availability of health services, their utilization and health outcomes. The researcher has used statistical tools like Standard Deviation, Coefficient of Variation and Disparity Ratio (Based on the model used in Bhattacharya, 2009) to analyse the interstate variations concerning various health parameters.

\section{Life Expectancy at Birth Rate in Odisha}

Life expectancy at birth means the average number of years a newborn could expect to live if; he/she was to pass through life subject to age-specific death rates of a given period. Growth rates have been calculated from 1992-93 to 2018-19 taking both all districts of Odisha and its 30 districts into consideration.

It is defined as the number of years that a newborn would live under mortality conditions prevailing at that time.

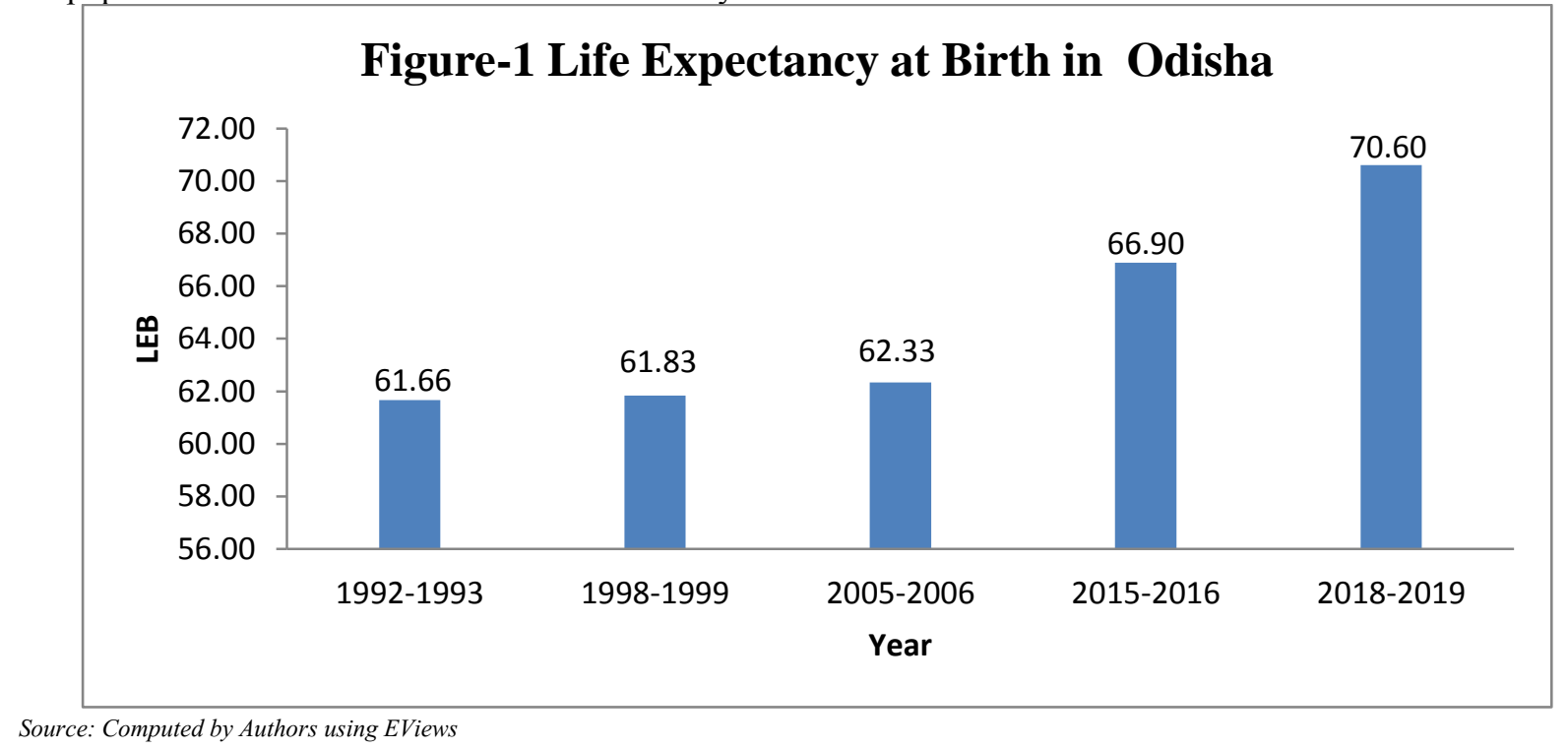

Figure-1 shows the life expectancy at birth in Odisha during all five NFHS database. The LEB has been increased from NFHS-1 data that is 1992-1993 to NFHS-5, i.e., 2018-19. Moreover, it indicates that from 1992-93 to $1998-99$, it has been increased at a very slow rate and from 1998-99 to 2005-06, also at a slow rate. But after 2005-06, it has been increased in a little bit higher rate up to 2018-19.
LEB (1992-93), during this period, Odisha's LEB is 61.66 across the districts. It implies that LEB as an indicator of health status had shown improvement in this decade in all the districts in Odisha because people had better access to modern facilities and led a better quality of life. In Cuttack and Puri, the growth rate was 68 while a better position by Sambalpur and Jharsuguda growth rate was 66 . The mean value of 


\section{SJIF Impact Factor 2021: 8.013| ISI I.F.Value:1.241| Journal DOI: 10.36713/epra2016 ISSN: 2455-7838(Online) EPRA International Journal of Research and Development (IJRD) Volume: 6 | Issue: 4 | April 2021

LEB in all districts is 61.66. Among all districts, LEB growth rate was Anugul (62); Balangiri (55), Gajapati (52), Kendrapada (57), Kendujhar (58), Kendujhar (58), and Malkangiri (53) were the districts where LEB was lower than the state average. LEB (1998-99), during this period, Odisha's LEB is 61.83 across the districts. The LEB has been increased as compared to 1992-93 that is 61.66. It implies that due to some modern facilities in the Health care sector the health status has been increased. Moreover, the SD is 3.82 and the mean is 61.83 . Therefore, the $\mathrm{CV}$ is $6.17 \%$. LEB (2005-06), here, the LEB in Odisha is 62.33 which are a little bit better compared to the previous two NFHS data. The mean is 62.33 and the SD is 3.46 there for is $\mathrm{CV}$ is $5.55 \%$. LEB (2015-16), here, the LEB is 66.90 which are far better than NFHS-1, NFHS-2 and NFHS3 data.

\section{Crude Birth Rate in Odisha}

The Crude Birth rate is an important indicator of health status. It refers to the ratio of the number of live births in a year to the mid-year population, normally expressed per thousand of population. It is defined as the total number of births per year per 1000 of the population.

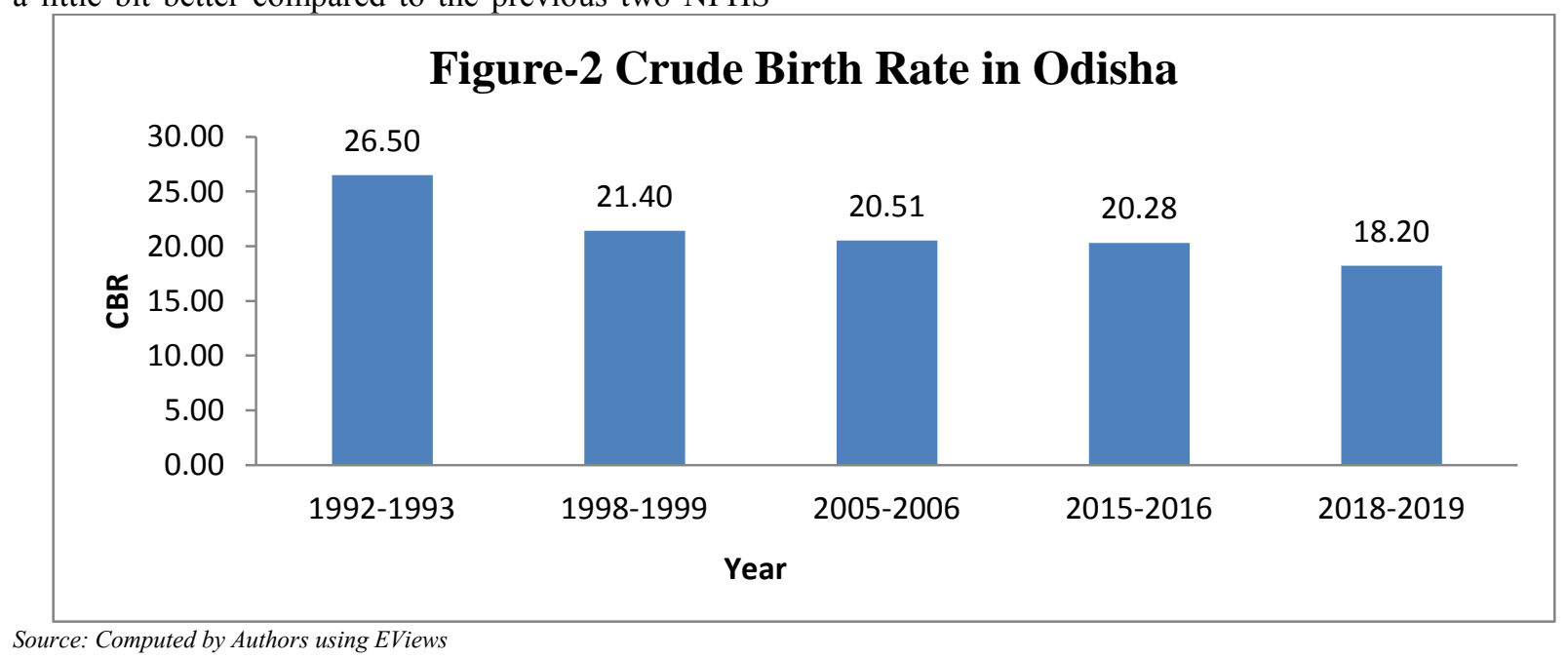

Figure- 2 shows the crude birth rate in Odisha during all five NFHS database. The CBR has been decreased from NFHS-1 data that is 1992-1993 to NFHS-5, i.e., 2018-19. Moreover, it indicates that from 1992-93 to 1998-99, it has been decreased at a very slow rate and from 1998-99 to 2018-19, also at a slow rate. But after 2005-06, it has been decreased in sharp rate up from 1992-93 to $1998-99$.

CBR (1992-93), during this period, Odisha's CBR is 26.50 across the districts. It implies that CBR as an indicator of health status had shown improvement in this decade in all the districts in Odisha because people had better access to modern facilities and led a better quality of life. In Cuttack and Puri, the growth rate was 68 while a better position by Sambalpur and Jharsuguda growth rate was 66 . The mean value of LEB in all districts is 61.66. During this period, Odisha's CBR is 21.40 across the districts. The CBR has been increased as compared to 1992-93 that is 26.50. It implies that due to some modern facilities in the Health care sector the health status has been increased. Moreover, the SD is 2.74 and the mean is 21.40. Therefore, the CV is $12.82 \%$. CBR (2005-06), here, the CBR is 20.51 which are far better than NFHS1 , NFHS-2 and NFHS-3 data. The mean is 20.51 and the $\mathrm{SD}$ is 2.75 there for is $\mathrm{CV}$ is $13.39 \%$. CBR (201516), here, the CBR is 20.28 which are far better than NFHS-1, NFHS-2 and NFHS-3 data.

\section{Infant Mortality Rate in Odisha}

Generating robust estimates of Infant Mortality Rate at the district level has become an almost necessity as a reduction in Infant Mortality constitutes one of the key targets in the reproductive \& Child Health Programme ( $\mathrm{RCH})$ under the umbrella of NRHM. This would also facilitate effective tracking of the Millennium Development Goal 4 on Child Mortality. The infant Mortality Rate has therefore been taken as the decisive indicator for estimation of sample size at the district level. 


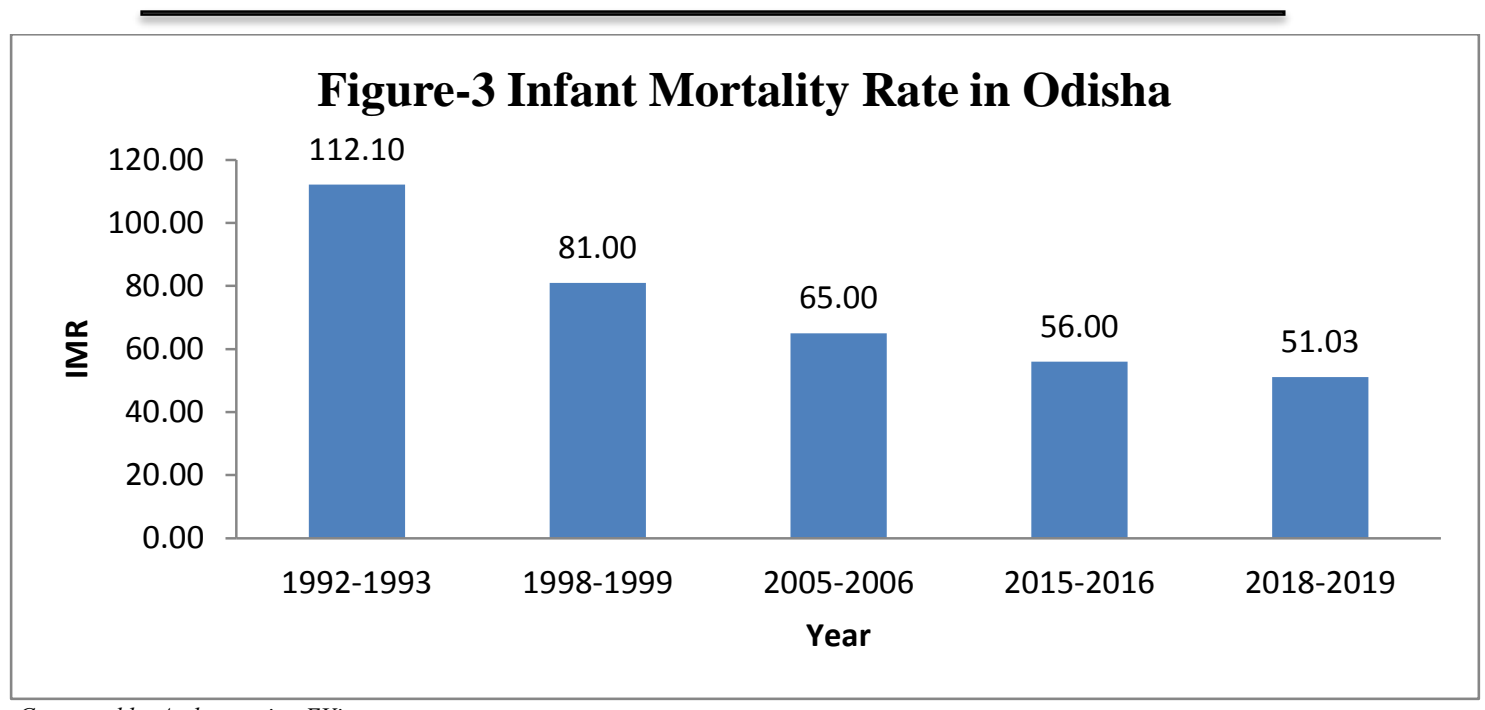

Source: Computed by Authors using EViews

Figure-3 shows the Infant Mortality Rate in Odisha during all five NFHS database. The Infant Mortality Rate has been decreased from NFHS-1 data that is 1992-1993 to NFHS-5, i.e. 2018-19. Moreover, it indicates that from 1992-93 to 1998-99, it has been decreased at a very slow rate and from 1998-99 to 2018-19, also at a low rate. But after 2005-06, it has been decreased in sharp rate up from 1992-93 to 199899.

IMR (1992-93), during this period, Odisha's IMR is 112.10 across the districts. It implies that IMR as an indicator of health status had shown improvement in this decade in all the districts in Odisha. The mean value of IMR in all districts is 112.10. IMR (1998-99), during this period, Odisha's IMR is 81.00 across the districts. The IMR has been increased as compared to 1992-93 that is 26.50. It implies that due to some modern facilities in the Health care sector the health status has been increased. IMR (2005-06), here, the IMR is 65.00 which are far better than NFHS-1, NFHS2 and NFHS-3 data. The mean is 65.00 and the SD is 12.88 there for is $\mathrm{CV}$ is $19.81 \%$. IMR (2015-16), here, the IMR is 56.00 which are far better than NFHS-1, NFHS-2 and NFHS-3 data.

\section{Doctors in Server per average population in Odisha}

An important indicator of health status is Health Personnel serving per ' 000 of the population. To find out the increase in the number of Health Personnel per ' 000 of the population served, the simple average growth rates have been worked out for all the three respective periods of the study and both rural and urban areas. An increase in its growth rate signifies a better position of health services.

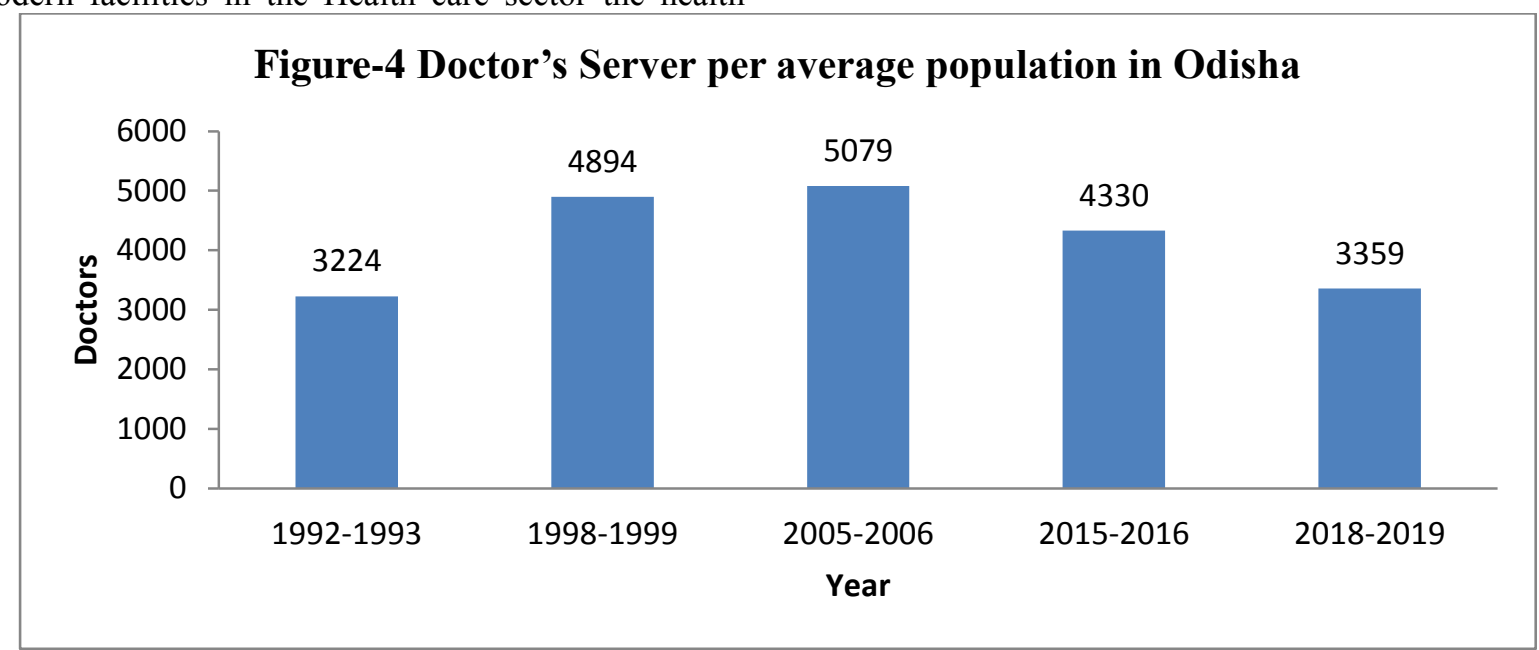

(C) 2021 EPRA IJRD | Journal DOI: https://doi.org/10.36713/epra2016 |www.eprajournals.com |335 | 


\section{SJIF Impact Factor 2021: 8.013| ISI I.F.Value:1.241| Journal DOI: 10.36713/epra2016 ISSN: 2455-7838(Online) EPRA International Journal of Research and Development (IJRD) Volume: 6 | Issue: 4 | April 2021

Figure-4 shows the Doctors per Average Population in Odisha during all five NFHS database. The Doctors per Average Population has been decreased from NFHS-1 data that is 1992-1993 to NFHS-5, i.e. 2018-19. Moreover, it indicates that from 1992-93 to 1998-99, it has been decreased at a very low rate and from 1998-99 to 2018-19, also at a low rate. But three NFHS differences in Doctors per Average Population ratio is higher than other the NFHS-1 and NFHS-2 after that, it has been decreased in sharp rate up from 1992-93 to 1998-99.

Doctors per Average Population (1992-93), during this period, Odisha's Doctors per Average Population are 107.47 across the districts. It implies that Doctors per Average Population as an indicator of health status had shown improvement in this decade in all the districts in Odisha.

Doctors per Average Population (1998-99), during this period, Odisha's Doctors per Average Population are 163.16 across the districts. The Doctors per Average Population have been decreased as compared to $1992-93$ that is 163.13 . It implies that due to some modern facilities in the Health care sector the health status has been decreased. Moreover, the SD is
132.91 and the mean is 163.13 . Therefore, the $\mathrm{CV}$ is $81.47 \%$.

Doctors per Average Population (2005-06), here, the doctors per Average Population are 169.30 which are far better than NFHS-1, NFHS-2 and NFHS3 data. The mean is 163.13 and the SD is 120.82 there for is $\mathrm{CV}$ is $71.36 \%$. Doctors per Average Population (2015-16), here, the doctors per Average Population are 144.33 which are far better than NFHS-2 and NFHS-3 data. Doctors per Average Population (2018-19), here, the doctors per Average Population are 111.97 which are also the lowest than all previous NFHS data set.

\section{Hospital server per Average population}

All hospitalised healthcare institution providing patient treatment with specialized staff and equipment. The best-known type of hospital is the general hospital, which has an emergency department. A district hospital typically is the major health care facility in its region, with large numbers of beds for intensive care and long term care.

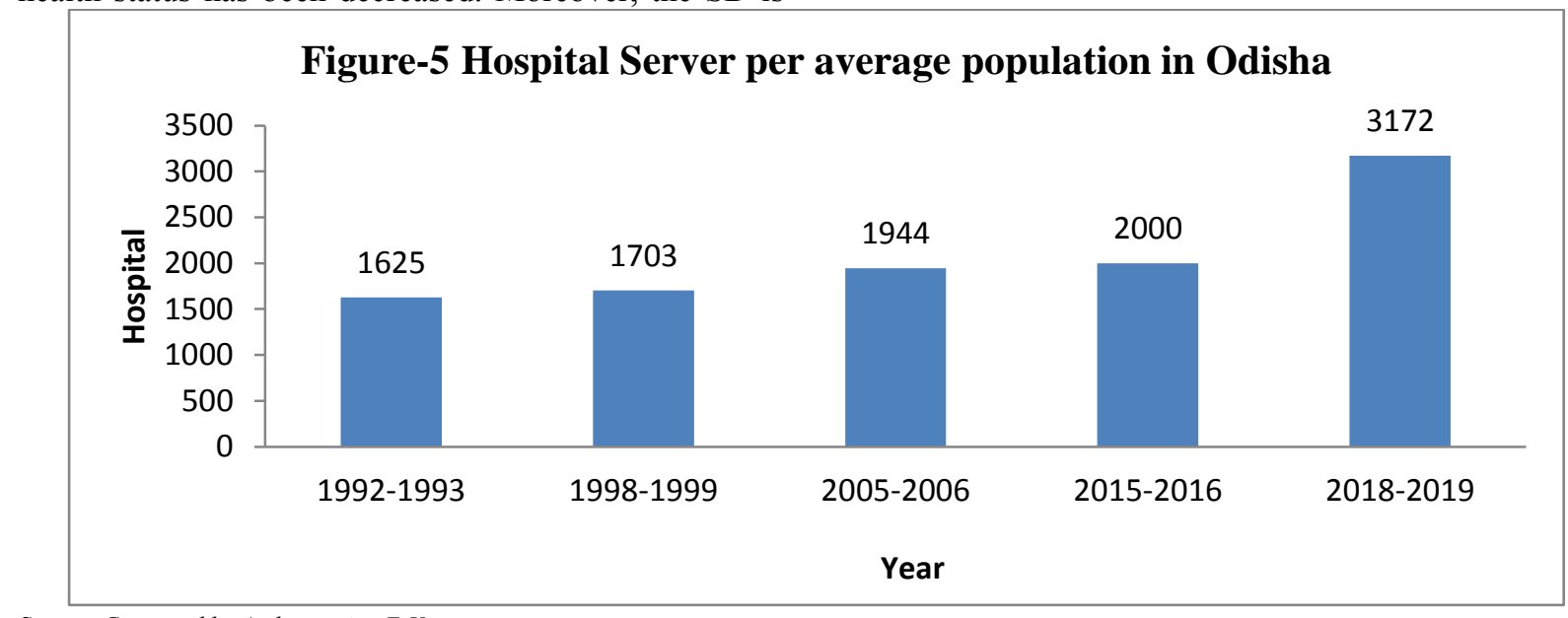

Source: Computed by Authors using E-Views

Figure-5 shows the Hospital server per Average population in Odisha during all five NFHS database. The Hospital server per Average population has been decreased from NFHS-1 data that is 1992-1993 to NFHS-5, i.e. 2018-19. Moreover, it indicates that from $1992-93$ to $1998-99$, it has been decreased at a very low rate and from 1998-99 to 2018-19, also at a low rate. But three NFHS differences in Hospital server per Average population ratio is higher than other the
NFHS-1 and NFHS-2 after that, it has been decreased in sharp rate up from 1992-93 to 1998-99.

Hospital server per Average population (1992-93), during this period, Odisha's Hospital server per Average population is 54.17 across the districts. It implies that Hospital server per Average population as an indicator of health status had shown improvement in this decade in all the districts in Odisha. The mean value of Hospital server per Average population in all districts is 54.17. Hospital server per Average 


\section{SJIF Impact Factor 2021: 8.013| ISI I.F.Value:1.241| Journal DOI: 10.36713/epra2016 ISSN: 2455-7838(Online) EPRA International Journal of Research and Development (IJRD)

population (1998-99), during this period, Odisha's Hospital server per Average population is 56.77 across the districts. The Hospital server per Average population has been decreased as compared to 1992-93 that is 56.77. It implies that due to some modern facilities in the Health care sector the health status has been decreased. Therefore, the $\mathrm{CV}$ is $46.22 \%$. Hospital server per Average population (200506), Here, the Hospital server per Average population is 64.80 which are far better than NFHS-1, NFHS-2 and NFHS-3 data. The mean is 64.80 and the SD is 28.78 there for is $\mathrm{CV}$ is $44.41 \%$. Hospital server per Average population (2015-16), Here, the Hospital server per Average population is 66.77 which are far better than NFHS-2 and NFHS-3 data. Hospital server per Average population (2018-19), Here, the Hospital server per Average population is 105.73 which is also lowest than all previous NFHS data set.

\section{Hospital Beds server per Average population in Odisha}

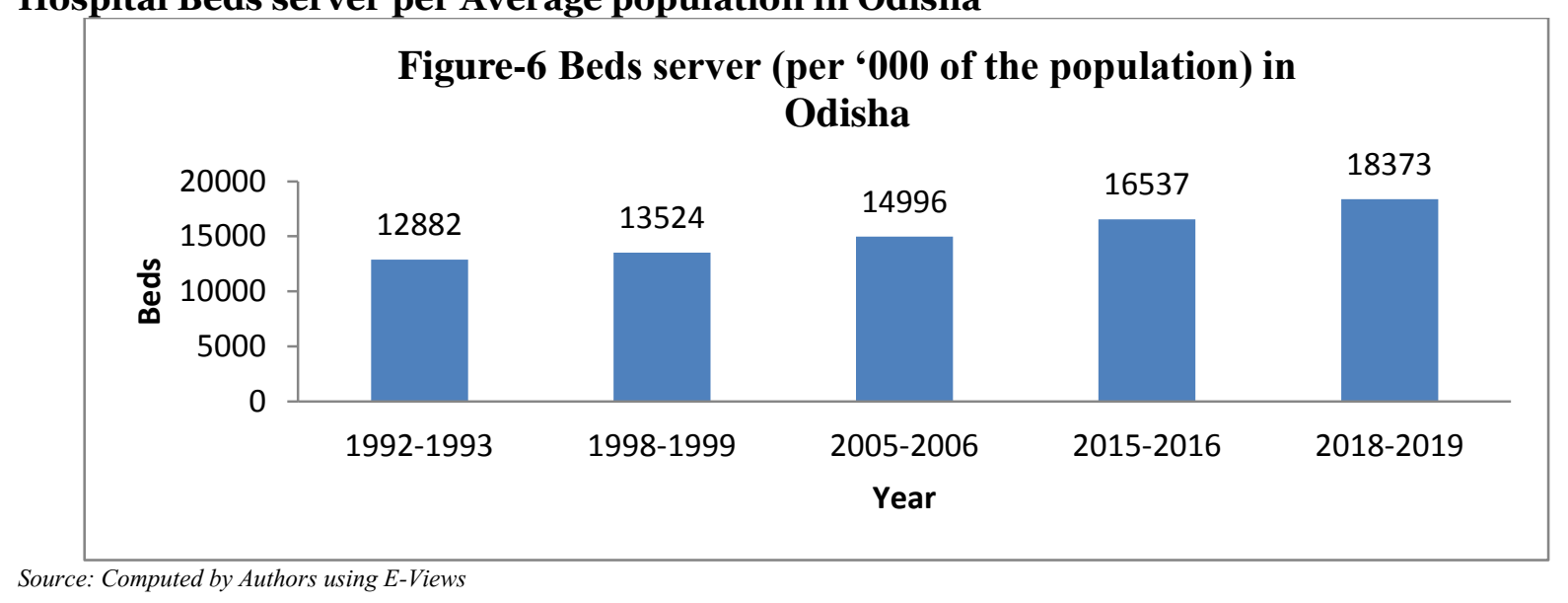

Figure-6 shows the Hospital Beds server per Average population in Odisha during all five NFHS database. The Hospital Beds server per Average population has been increased from NFHS-1 data that is 1992-1993 to NFHS-5, i.e. 2018-19. Moreover, it indicates that from $1992-93$ to $1998-99$, it has been decreased at a very low rate and from 1998-99 to 2018-19, also at a hights rate. But three NFHS differences in Hospital Beds server per Average population ratio is higher than other the NFHS-1 and NFHS-2 after that, it has been decreased in sharp rate up from 1992-93 to 1998-99.

Hospital Beds server per Average population (1992-93), during this period, Odisha's Hospital Beds server per Average population is 429.40 across the districts. It implies that Hospital Beds server per Average population as an indicator of health status had shown improvement in this decade in all the districts in Odisha. The mean value of Hospital Beds server per Average population in all districts is 429.40. Hospital Beds server per Average population (1998-99), during this period, Odisha's Hospital Beds server per Average population is 450.80 across the districts. The hospital beds server per Average population has been decreased as compared to 1992-93 that is 450.80 . It implies that due to some modern facilities in the Health care sector the health status has been decreased. Moreover, the SD is 205.67 and the mean is 450.80 . Therefore, the $\mathrm{CV}$ is $45.62 \%$. Hospital Beds server per Average population (2005-06), Here, the Hospital Beds server per Average population is 499.87 which is far better than NFHS-1, NFHS-2 and NFHS-3 data. Hospital Beds server per Average population (2015-16), Here, the Hospital Beds server per Average population is 551.23which is far better than NFHS-2 and NFHS-3 data. The mean is 551.23 and the SD is 502.44there for is CV is $91.15 \%$. Hospital Beds server per Average population (2018-19), Here, the hospital beds server per Average population is 612.43 which is also lowest than all previous NFHS data set.

\section{Literacy Rate of Odisha}

Any person who can read and write with understanding in any language is recorded as literate (Jana, N. C. \& Ghosh, P. K., 2015). 
SJIF Impact Factor 2021: 8.013| ISI I.F.Value:1.241| Journal DOI: 10.36713/epra2016 ISSN: 2455-7838(Online) EPRA International Journal of Research and Development (IJRD) Volume: 6 | Issue: 4 | April 2021 - Peer Reviewed Journal

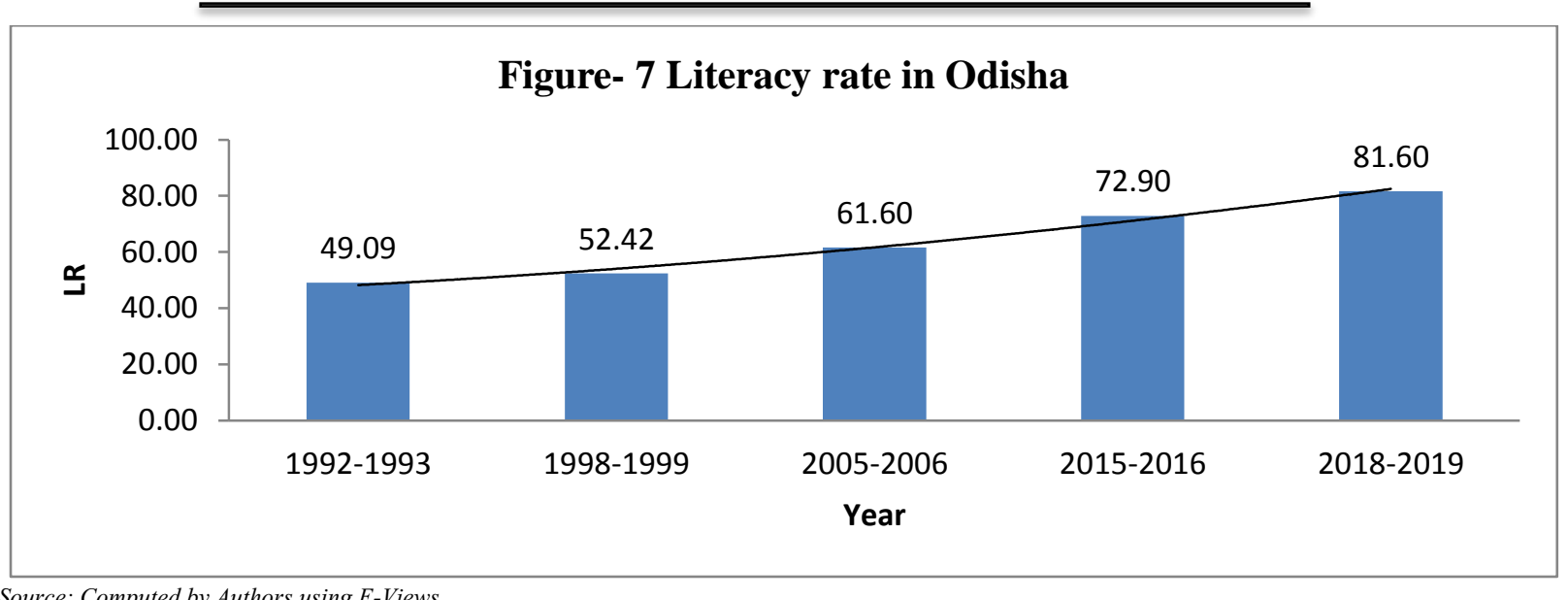

Source: Computed by Authors using E-Views

Figure-7 shows the Literacy Rate population in Odisha during all five NFHS database. The Literacy Rate population has been increased from NFHS-1 data that is 1992-1993 to NFHS-5, i.e. 2018-19. Moreover, it indicates that from $1992-93$ to $1998-99$, it has been decreased at a very low rate and from 1998-99 to 201819 , also at a hights rate. But three NFHS a difference in Literacy Rate population ratio is higher than other the NFHS-1 and NFHS-2 after that, it has been decreased in sharp rate up from 1992-93 to 1998-99.

Literacy Rate (1992-93), during this period, Odisha's Literacy Rate population is 45.60 across the districts. It implies that the Literacy Rate population as an indicator of health status had shown improvement in this decade in all the districts in Odisha. The mean value of the Literacy Rate population in all districts is 45.60. Literacy rates studies show that literacy rates are directly related to the health status of the population. During this period, at an all Odisha level, the total Literacy rate of Odisha was $49.09 \%$. Gajapati ($0.87 \%)$, Kalahandi (-0.69\%), Koraput (-1.75\%), Nabarangapur $(-1.03 \%)$, Rayagada $(-1.43 \%)$, were the districts having a rate of change in lower than the higher districts in Baleshwar $(0.33 \%)$, Bhadrak $(0.32 \%)$, Sambalpur $\quad(0.50 \%)$, Ganjam (0.37\%), Nayagarh $(0.52 \%)$, Sambalpur $(0.50 \%)$ were the districts having heights than districts average among the State. Literacy Rate (1998-99), during this period,
Odisha's Literacy Rate of the population is 50.89 across the districts. The Literacy Rate of the population has been decreased as compared to 1992-93 that is 450.80. It implies that due to some modern facilities in the Health care sector the health status has been decreased. Moreover, the SD is 9.01 and the mean is 50.89. Therefore, the $\mathrm{CV}$ is $17.70 \%$. Literacy Rate (2005-06), here, the Literacy Rate of the population is 60.51 which are far better than NFHS-1, NFHS-2 and NFHS-3 data.

\section{Sex Ratio of Odisha}

Sex ratio is defined as the number of females per thousand males. According to the 2011census, the sex ratio for India's population is 1072 . This ratio is significantly higher than those of neighbouring countries- Pakistan (1066), China (10590) and Bangladesh (1049). For India, in 2001 there was a slight improvement. This gain can be attributed to better health facilities for women and some extent to improvement in the status of women. But any complacency over this development must be tempered by the fact that there are sharp differences across states. It is unclear whether the cause for this imbalance is outmigration of the male labour force in Kerala and inmigration of male workers in Haryana or systematic use of sex-selective abortion. 


\section{SJIF Impact Factor 2021: 8.013| ISI I.F.Value:1.241| Journal DOI: 10.36713/epra2016 ISSN: 2455-7838(Online) EPRA International Journal of Research and Development (IJRD) Volume: 6 | Issue: 4 | April 2021

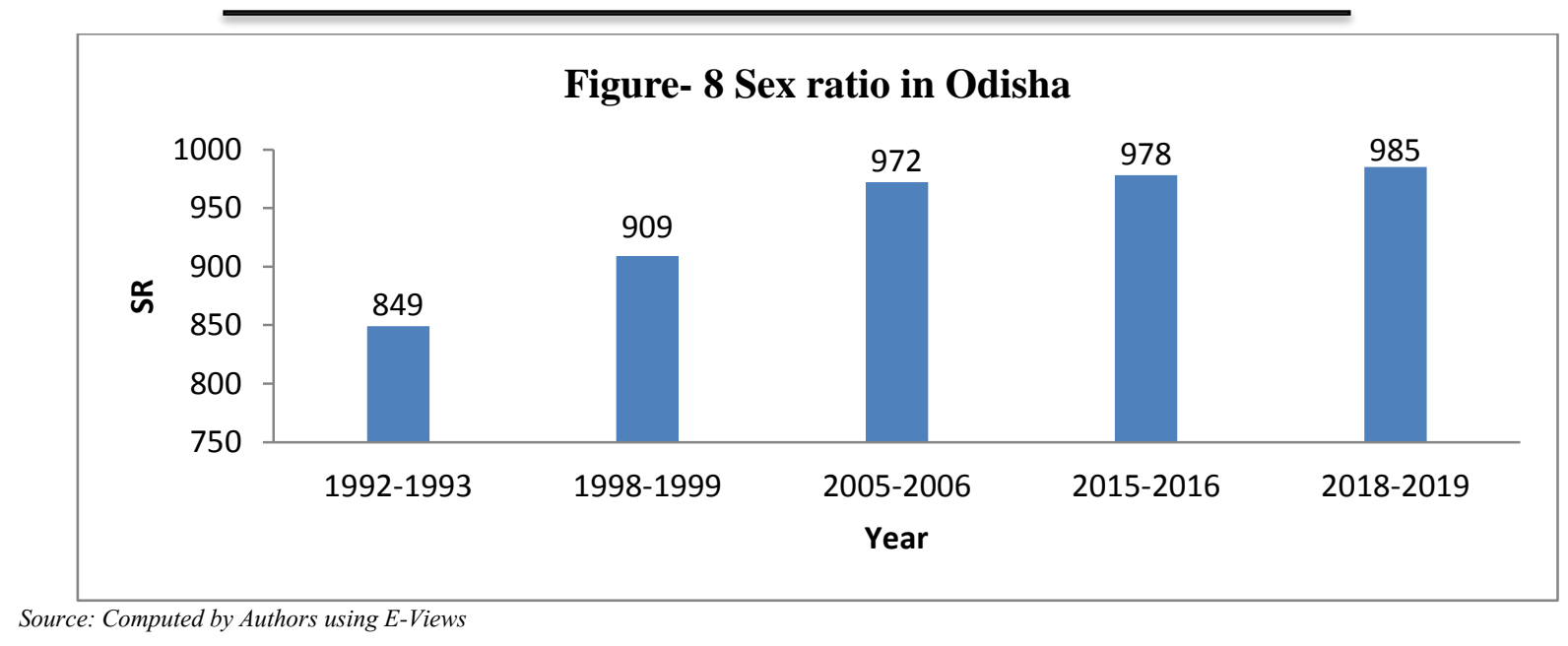

Figure-8 shows the Sex Ratio population in Odisha during all five NFHS database. The Sex Ratio population has been increased from NFHS-1 data that is $1992-1993$ to NFHS-5, i.e. 2018-19. Moreover, it indicates that from 1992-93 to 1998-99, it has been decreased at a very low rate and from 1998-99 to 201819 , also at a heights rate. But three NFHS a difference in Sex Ratio population ratio is higher than other the NFHS-1 and NFHS-2 after that, it has been decreased in sharp rate up from 1992-93 to 1998-99.

Sex Ratio (1992-93), during this period, Odisha's Sex Ratio Average population is 849.00 across the districts. It implies that the Sex Ratio per Average population as an indicator of health status had shown improvement in this decade in all the districts in Odisha. The mean value of Sex Ratio Average population in all districts is 849.00. Sex Ratio (1998-
99), during this period, Odisha's Sex Ratio Average population is 909.00 across the districts. The Sex Ratio Average population have been decreased as compared to 1992-93 that is 909.00. It implies that due to some modern facilities in the Health care sector the health status has been decreased. Moreover, the SD is 31.54 and the mean is 909.00 . Therefore, the CV is $3.77 \%$. Sex Ratio (2005-06), here, the Sex Ratio Average population is 983.30 which are far better than NFHS-1, NFHS-2 and NFHS-3 data.

\section{Crude Death Rate in Odisha}

It is defined as the total number of deaths per year per 1000 people. It is calculated as under D/P *1000Where $\mathrm{D}$ is several deaths, $\mathrm{P}$ is mid-year population.

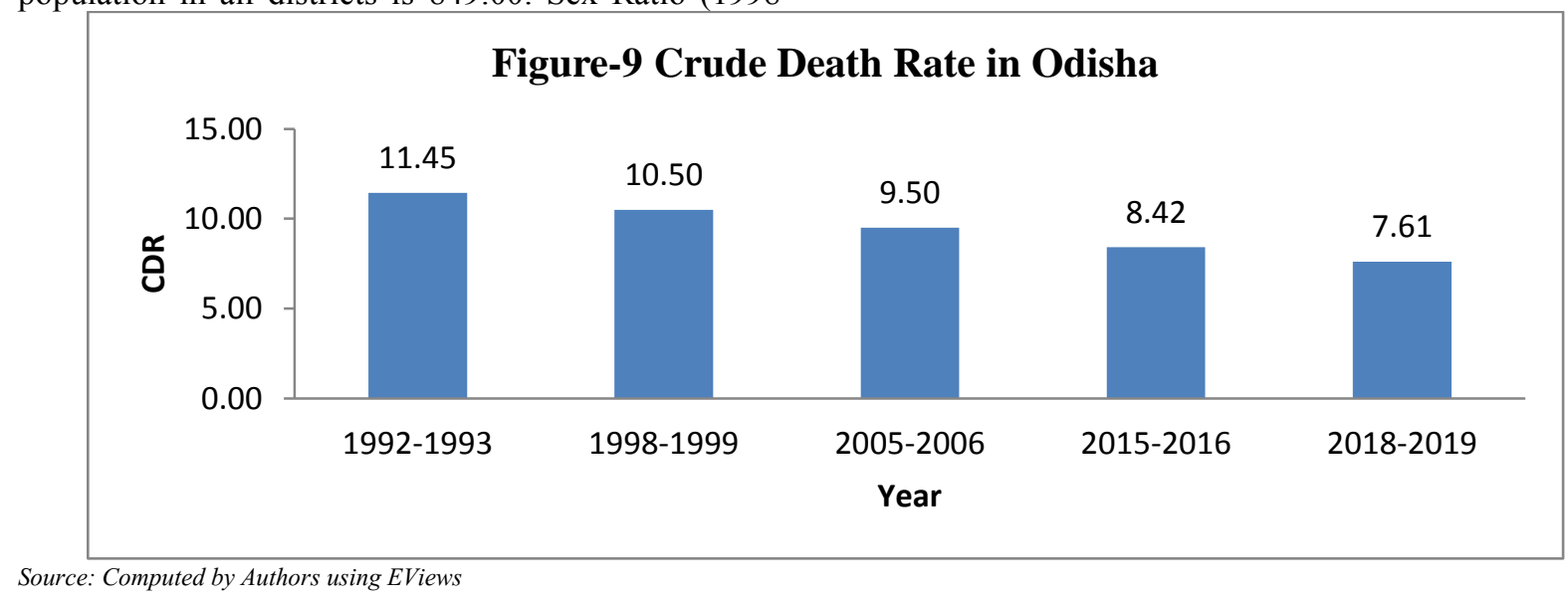

Figure-9 shows the CDR population in Odisha during all five NFHS database. The CDR population has been decreased from NFHS-1 data that is 1992-1993 to
NFHS-5, i.e. 2018-19. Moreover, it indicates that from $1992-93$ to $1998-99$, it has been increased at a very low rate and from 1998-99 to 2018-19, also at a heights 


\section{SJIF Impact Factor 2021: 8.013| ISI I.F.Value:1.241| Journal DOI: 10.36713/epra2016 ISSN: 2455-7838(Online) EPRA International Journal of Research and Development (IJRD)}

rate. But three NFHS differences in CDR population ratio are higher than other the NFHS-1 and NFHS-2 after that, it has been increased in sharp rate up from 1992-93 to 1998-99.

CDR (1992-93), during this period, Odisha's CDR of the population is 11.45 across the districts. It implies that the CDR population as an indicator of health status had shown improvement in this decade in all the districts in Odisha. The mean value of the CDR population in all districts is 11.45. CDR (1998-99), during this period, Odisha's CDR population is 10.50 across the districts. The CDR population have been decreased as compared to $1992-93$ that is 10.50 . It implies that due to some modern facilities in the Health care sector the health status has been decreased.

\begin{tabular}{|c|c|c|c|c|c|c|c|c|c|c|}
\hline \multicolumn{11}{|c|}{ Table-10 Availability of Public Health care (1992-2019) in Odisha } \\
\hline Districts & LEB & CBR & IMR & Doctors & Hospitals & Beds & LR & SR & CDR & Rank \\
\hline Odisha & 64.66 & 21.38 & 73.03 & 4177.20 & 2088.80 & 15262.40 & 63.52 & 938.60 & 9.50 & - \\
\hline Anugul & 65.50 & 19.16 & 67.41 & 103.60 & 51.60 & 356.80 & 68.68 & 908.20 & 8.56 & 21 \\
\hline Balangir & 60.10 & 20.75 & 118.50 & 157.20 & 81.80 & 501.00 & 62.26 & 961.80 & 11.50 & 9 \\
\hline Baleshwar & 66.80 & 19.75 & 65.34 & 113.20 & 100.00 & 484.80 & 71.33 & 934.60 & 8.29 & 11 \\
\hline Bargarh & 66.22 & 19.04 & 79.47 & 105.00 & 72.80 & 340.00 & 67.62 & 914.80 & 11.43 & 19 \\
\hline Baudh & 65.20 & 25.76 & 72.99 & 123.80 & 21.00 & 261.80 & 60.35 & 958.60 & 10.59 & 21 \\
\hline Bhadrak & 67.64 & 21.39 & 69.07 & 66.20 & 69.20 & 322.20 & 70.49 & 910.60 & 9.42 & 20 \\
\hline Cuttack & 69.40 & 20.61 & 71.62 & 587.40 & 97.00 & 1536.80 & 76.74 & 998.20 & 7.61 & 1 \\
\hline Debagarh & 69.28 & 19.85 & 74.53 & 28.40 & 14.80 & 986.80 & 63.91 & 964.40 & 9.60 & 4 \\
\hline Dhenkanal & 69.60 & 21.56 & 78.59 & 123.00 & 58.60 & 485.80 & 70.46 & 914.20 & 12.18 & 10 \\
\hline Gajapati & 59.26 & 20.37 & 69.41 & 54.40 & 35.80 & 237.80 & 46.44 & 959.20 & 8.72 & 20 \\
\hline Ganjam & 63.54 & 19.69 & 69.71 & 299.60 & 144.20 & 1199.00 & 62.36 & 932.80 & 9.27 & 1 \\
\hline Jagatsinghapur & 63.66 & 18.74 & 64.19 & 78.20 & 52.80 & 282.80 & 75.29 & 846.40 & 8.47 & 19 \\
\hline Jajapur & 64.12 & 19.52 & 65.40 & 81.20 & 80.40 & 447.80 & 70.16 & 936.60 & 8.58 & 11 \\
\hline Jharsuguda & 67.84 & 19.47 & 61.45 & 44.40 & 27.00 & 199.40 & 70.70 & 915.00 & 9.60 & 18 \\
\hline Kalahandi & 64.44 & 19.79 & 71.80 & 140.60 & 81.40 & 456.80 & 52.11 & 952.60 & 7.92 & 8 \\
\hline Kandhamal & 63.70 & 21.89 & 100.75 & 100.60 & 73.20 & 431.60 & 58.25 & 955.00 & 9.58 & 8 \\
\hline Kendrapara & 61.92 & 20.59 & 75.67 & 93.20 & 62.00 & 322.20 & 75.19 & 988.00 & 10.28 & 10 \\
\hline Kendujhar & 63.18 & 20.11 & 70.93 & 141.00 & 108.80 & 484.40 & 64.94 & 958.60 & 9.99 & 6 \\
\hline Khordha & 65.86 & 19.51 & 81.72 & 214.40 & 93.20 & 693.40 & 78.49 & 904.60 & 8.96 & 3 \\
\hline Koraput & 65.10 & 24.20 & 65.12 & 110.40 & 82.20 & 443.80 & 41.55 & 964.20 & 9.61 & 6 \\
\hline Malkangiri & 60.26 & 24.05 & 63.37 & 58.20 & 46.00 & 265.60 & 41.85 & 984.40 & 8.85 & 11 \\
\hline Mayurbhanj & 65.90 & 24.35 & 65.76 & 224.20 & 146.40 & 722.80 & 56.89 & 955.80 & 10.61 & 2 \\
\hline Nabarangapur & 65.48 & 23.75 & 65.12 & 96.40 & 65.20 & 277.20 & 39.72 & 968.80 & 8.78 & 7 \\
\hline Nuapada & 63.60 & 23.22 & 67.86 & 63.20 & 30.60 & 298.00 & 56.11 & 947.60 & 8.52 & 7 \\
\hline Nayagarh & 66.78 & 22.40 & 76.74 & 60.20 & 57.20 & 446.20 & 65.15 & 888.80 & 9.92 & 6 \\
\hline Puri & 69.72 & 20.24 & 89.97 & 142.60 & 74.00 & 667.20 & 76.32 & 928.20 & 9.83 & 3 \\
\hline Rayagada & 61.40 & 23.96 & 71.34 & 170.40 & 67.60 & 284.40 & 43.45 & 978.00 & 9.44 & 4 \\
\hline Sambalpur & 65.61 & 22.14 & 65.86 & 369.60 & 54.20 & 859.20 & 69.10 & 943.00 & 10.73 & 1 \\
\hline Sonapur & 64.35 & 23.33 & 67.08 & 59.20 & 34.40 & 306.20 & 64.59 & 927.40 & 8.82 & 3 \\
\hline Sundargarh & 62.94 & 22.20 & 64.07 & 167.40 & 106.00 & 660.60 & 68.04 & 943.20 & 9.24 & 1 \\
\hline Mean & 64.95 & 21.38 & 73.03 & 139.24 & 69.65 & 508.75 & 62.95 & 941.45 & 9.50 & - \\
\hline SD & 12.58 & 2.76 & 12.61 & 120.52 & 32.38 & 457.25 & 12.01 & 45.93 & 1.15 & - \\
\hline $\mathrm{CV}$ & 3.88 & 13.10 & 18.33 & 89.13 & 46.44 & 91.46 & 20.23 & 4.83 & 12.41 & - \\
\hline
\end{tabular}

Source: Computed by Authors

Table-10 represents important indicators of the health status of all the districts of Odisha. The rank column presents the position of the districts in nine indicators on the whole. With consistency knowledge, four districts are the first rank in all nine indicators among all districts. They are Ganjam, Cuttack, Sundaragada, Sambalpur follow by the subsequent ranks, i.e, Maurabhanja, Khurda, Debagarda, Kenjhara, Koraput, Nayagada and so on. The least ranks are Anugul, Bhadraka, Gajapati, Jagatasingpur, Baragada, Jharsuguda, Baleshwar, Malanigiri, and Dhenkanal. In most cases, the district-wise disparities are there. The health indicators vary widely across the districts reflecting the differing levels of resources available. 


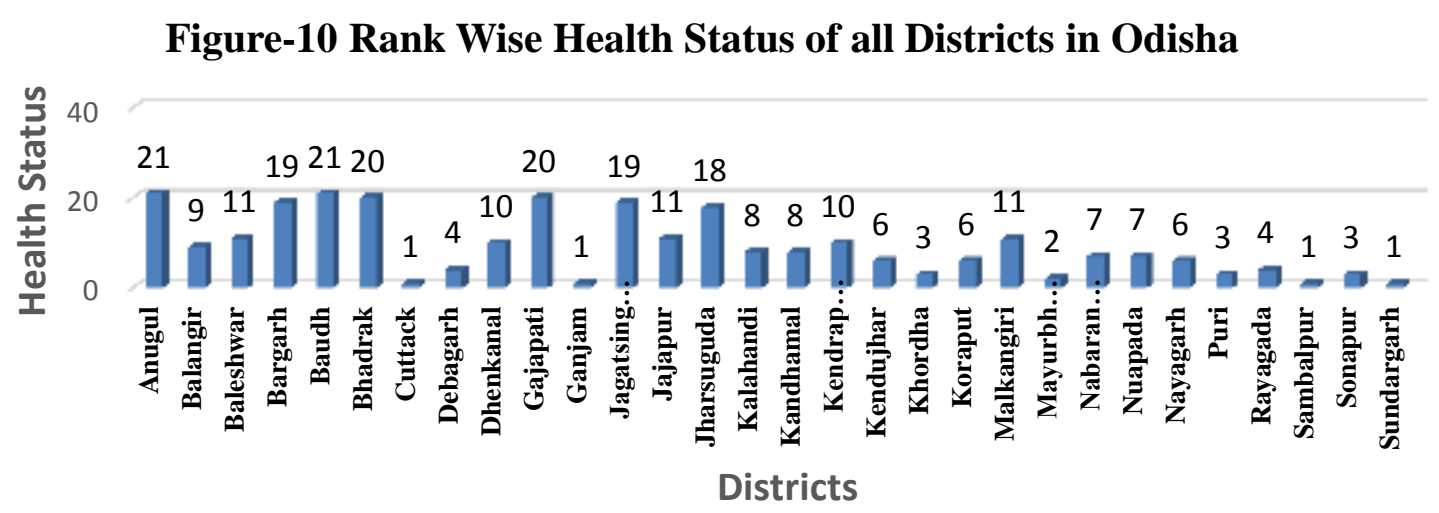

Source: Computed by Authors using EViews

Figure-10 represents important indicators of the health status of all the districts of Odisha. The lower the bar highest rank having of the states. Like Ganjam, Cuttack, Sundaragada, Sambalpur are having a low level of bars which shows the highest ranks and so on so forth. Similarly, the districts like Boudh, Anugul, Bhadraka, Gajapati, Jagatasingpur, Baragada, Jharsuguda, Baleshwar, Malanigiri, and Dhenkanal are having a high level of bars showing the lowest ranks regarding the health status.

Table-11 Empirical Results in Descriptive Statistics

\begin{tabular}{|l|c|c|c|c|c|c|c|c|c|}
\hline & LEB & CBR & IMR & Doctors & Hospital & Beds & LR & SR & CDR \\
\hline Mean & 64.94 & 21.38 & 73.03 & 269.50 & 134.78 & 984.67 & 62.97 & 941.36 & 9.50 \\
\hline Standard Error & 0.49 & 0.34 & 2.12 & 131.78 & 65.38 & 478.95 & 1.99 & 5.69 & 0.19 \\
\hline Median & 65.10 & 20.75 & 69.71 & 110.40 & 69.20 & 446.20 & 64.94 & 943.20 & 9.44 \\
\hline Standard Deviation & 2.74 & 1.91 & 11.79 & 733.70 & 364.03 & 2666.67 & 11.05 & 31.69 & 1.06 \\
\hline Kurtosis & -0.25 & -0.74 & 7.25 & 29.45 & 30.49 & 30.14 & -0.24 & 1.38 & 0.32 \\
\hline Skewness & -0.09 & 0.58 & 2.48 & 5.37 & 5.50 & 5.46 & -0.80 & -0.77 & 0.67 \\
\hline Range & 10.46 & 7.02 & 57.05 & 4148.80 & 2074.00 & 15063.00 & 38.77 & 151.80 & 4.57 \\
\hline Minimum & 59.26 & 18.74 & 61.45 & 28.40 & 14.80 & 199.40 & 39.72 & 846.40 & 7.61 \\
\hline Maximum & 69.72 & 25.76 & 118.50 & 4177.20 & 2088.80 & 15262.40 & 78.49 & 998.20 & 12.18 \\
\hline Count & 31.00 & 31.00 & 31.00 & 31.00 & 31.00 & 31.00 & 31.00 & 31.00 & 31.00 \\
\hline Confidence Level (95.0\%) & 1.00 & 0.70 & 4.32 & 269.12 & 133.53 & 978.14 & 4.05 & 11.63 & 0.39 \\
\hline
\end{tabular}

Source: Computed by Authors

The descriptive statistics are presented in Table-11 represents that the average LEB during the period is 64.94 while the maximum during that period is 69.72. the mean CBR is 21.38 while the maximum is 25.76 during that period the mean IMR is 73.03 , Doctors is 269.50 , Hospital is 134.78 , Beds is 984.64 , LR is 62.97 , SR is 941.36 and CDR is 9.50 during this period while the maximum is 118.50 in IMR is 4177.20 in doctors, 2088.80 in hospital, 1562.40 in beds 78.49 in LR, 998.20 in SR and 12.18 regarding CDR during this period. This indicates that the state is considered as highly backward regarding health infrastructure availability during the period of analysis.

\section{Health care status in Odisha}

The indicators for Crude Composite Index (CCI) include life expectancy at birth, Crude Birth Rate, Infant mortality rate, Health Personnel per ' 000 of population, Hospitals per ' 000 of population, Beds per ' 000 of population, Literacy Rate, Sex Ratio, and Crude Death Rate. First, the districts are ranked for each of the indicators. All the ranks for each district are then added up. The CCI has been estimated by taking the average of the total ranks of each district. After taking the average of the ranks, the districts is assigned with ranks in ascending order, i.e. the first ranked districts best achiever district having the lowest value of the indicators. 


\section{SJIF Impact Factor 2021: 8.013| ISI I.F.Value:1.241| Journal DOI: 10.36713/epra2016 ISSN: 2455-7838(Online) EPRA International Journal of Research and Development (IJRD)}

Volume: 6 | Issue: 4 | April 2021

- Peer Reviewed Journal

Table-12 Rate of change (RoC) in Health care status in Odisha (Per '000 people)

\begin{tabular}{|c|c|c|c|c|c|c|c|c|}
\hline Year & $\begin{array}{c}\text { Crude } \\
\text { Death } \\
\text { Rate } \\
\text { (RoC) }\end{array}$ & $\begin{array}{c}\text { Crude } \\
\text { Birth } \\
\text { Rate } \\
\text { (RoC) }\end{array}$ & $\begin{array}{c}\text { Lxpectancy } \\
\text { at Birth } \\
\text { (RoC) }\end{array}$ & $\begin{array}{c}\text { Literacy } \\
\text { Rate } \\
\text { (RoC) }\end{array}$ & $\begin{array}{c}\text { Infant } \\
\text { Mortality } \\
\text { Rate (RoC) }\end{array}$ & $\begin{array}{c}\text { Hospital } \\
\text { Beds } \\
\text { (RoC) }\end{array}$ & $\begin{array}{c}\text { Sex Ratio } \\
\text { at Birth } \\
\text { (RoC) }\end{array}$ & $\begin{array}{c}\text { Doctors } \\
\text { (RoC) }\end{array}$ \\
\hline 1992 & -- & -- & -- & -- & -- & -- & -- & -- \\
\hline 1993 & 0.09 & -0.03 & 0.01 & 0.02 & -0.02 & 0.04 & 0.00 & 0.04 \\
\hline 1994 & 0.07 & 0.01 & 0.00 & 0.01 & -0.06 & 0.03 & -0.01 & 0.04 \\
\hline 1995 & 0.00 & -0.04 & 0.01 & 0.01 & 0.00 & 0.02 & -0.01 & 0.02 \\
\hline 1996 & 0.00 & -0.03 & 0.02 & 0.01 & -0.07 & 0.03 & 0.00 & 0.00 \\
\hline 1997 & 0.01 & -0.02 & 0.00 & 0.01 & 0.00 & 0.07 & 0.02 & 0.00 \\
\hline 1998 & 0.02 & -0.03 & 0.02 & 0.02 & 0.02 & 0.03 & 0.00 & 0.00 \\
\hline 1999 & -0.04 & -0.05 & 0.00 & 0.05 & -0.01 & 0.05 & 0.01 & 0.11 \\
\hline 2000 & -0.02 & -0.01 & 0.00 & 0.08 & -0.02 & 0.02 & 0.00 & -0.07 \\
\hline 2001 & -0.03 & -0.03 & 0.05 & 0.05 & -0.05 & 0.02 & 0.00 & 0.01 \\
\hline 2002 & -0.04 & -0.01 & 0.02 & 0.01 & -0.03 & 0.03 & 0.00 & 0.27 \\
\hline 2003 & -0.01 & -0.01 & 0.01 & 0.01 & -0.05 & 0.02 & 0.00 & 0.04 \\
\hline 2004 & -0.01 & -0.01 & 0.00 & 0.00 & -0.07 & 0.00 & 0.00 & 0.17 \\
\hline 2005 & -0.01 & 0.01 & 0.01 & 0.02 & -0.03 & 0.00 & 0.00 & 0.02 \\
\hline 2006 & -0.02 & -0.05 & 0.01 & 0.02 & -0.03 & 0.00 & -0.04 & -0.04 \\
\hline 2007 & -0.01 & -0.02 & 0.00 & 0.02 & -0.03 & 0.01 & 0.00 & 0.01 \\
\hline 2008 & -0.02 & 0.00 & 0.01 & 0.01 & -0.03 & 0.04 & 0.00 & 0.01 \\
\hline 2009 & -0.03 & -0.02 & 0.00 & 0.03 & -0.06 & 0.02 & 0.00 & 0.04 \\
\hline 2010 & -0.01 & -0.02 & 0.02 & 0.01 & -0.06 & 0.03 & 0.00 & 0.17 \\
\hline 2011 & -0.01 & -0.02 & 0.01 & 0.02 & -0.07 & 0.01 & 0.01 & 0.13 \\
\hline 2012 & 0.00 & 0.07 & 0.00 & 0.00 & -0.07 & 0.02 & 0.00 & 0.14 \\
\hline 2013 & -0.01 & -0.01 & -0.03 & -0.05 & -0.04 & 0.02 & 0.01 & 0.05 \\
\hline 2014 & -0.06 & -0.02 & 0.01 & 0.01 & -0.04 & 0.01 & 0.00 & -0.24 \\
\hline 2015 & -0.01 & -0.09 & 0.01 & 0.00 & -0.06 & 0.01 & 0.00 & 0.16 \\
\hline 2016 & -0.03 & -0.03 & -0.03 & 0.00 & -0.04 & 0.01 & 0.00 & 0.06 \\
\hline 2017 & -0.03 & -0.02 & 0.02 & 0.00 & -0.07 & 0.07 & -0.05 & 0.07 \\
\hline 2018 & -0.01 & -0.01 & 0.00 & 0.00 & -0.02 & 0.01 & 0.05 & 0.01 \\
\hline 2019 & -0.03 & -0.01 & 0.02 & 0.00 & 0.00 & 0.02 & -0.01 & 0.01 \\
\hline 2020 & -0.01 & -0.01 & 0.00 & 0.03 & 0.00 & 0.01 & 0.05 & 0.00 \\
\hline
\end{tabular}

Table-12 represents the growth rate of all nine variables. The first column which is CDR decreases over the period from 1992 to 2020. Similarly, the CBR also decreases for the study. This indicates a little bit better health infrastructure in Odisha. Moreover, the LEB increases during the study period and the literacy rate also increase during the same period. IMR decreases over the period and the hospital beds (Per ' 000 people) is showing the increasing in trend but form
2002 to 2005 it is constant. After it is again increased. Sex Ratio at Birth is showing the negative growth for the first three-four years, but after 1996 it is in increasing in trend up to 2005. Again increasing up to 2016 followed by negative growth with again positive growth. In the case of Doctors (Per '000 people) which is in constant growth up to 2000, after this again it is in positive growth with fluctuation rate. 


\title{
SJIF Impact Factor 2021: 8.013| ISI I.F.Value:1.241| Journal DOI: 10.36713/epra2016 ISSN: 2455-7838(Online) EPRA International Journal of Research and Development (IJRD)
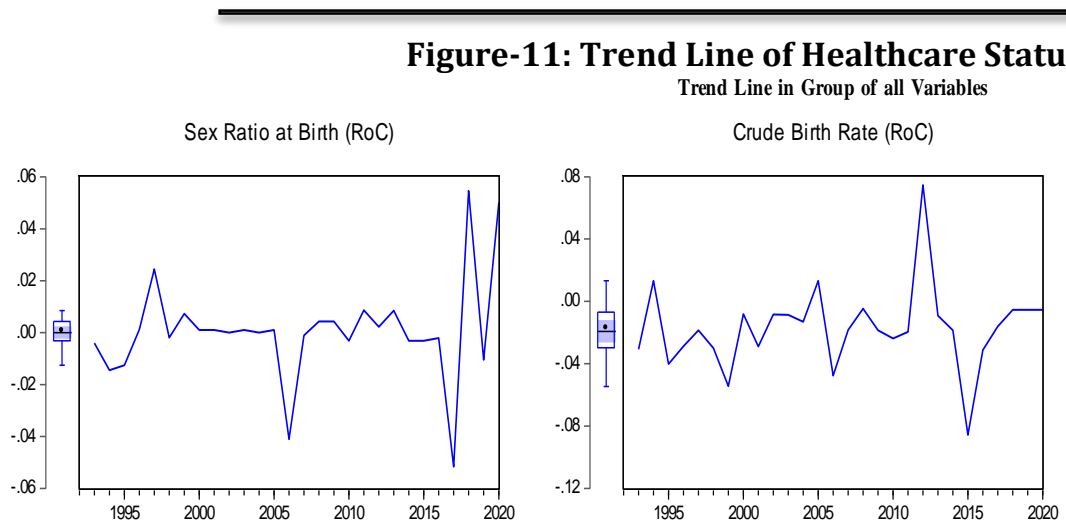

\author{
in Odisha
}

Trend Line in Group of all Variables

Doctors (Per '000 people) (RoC)
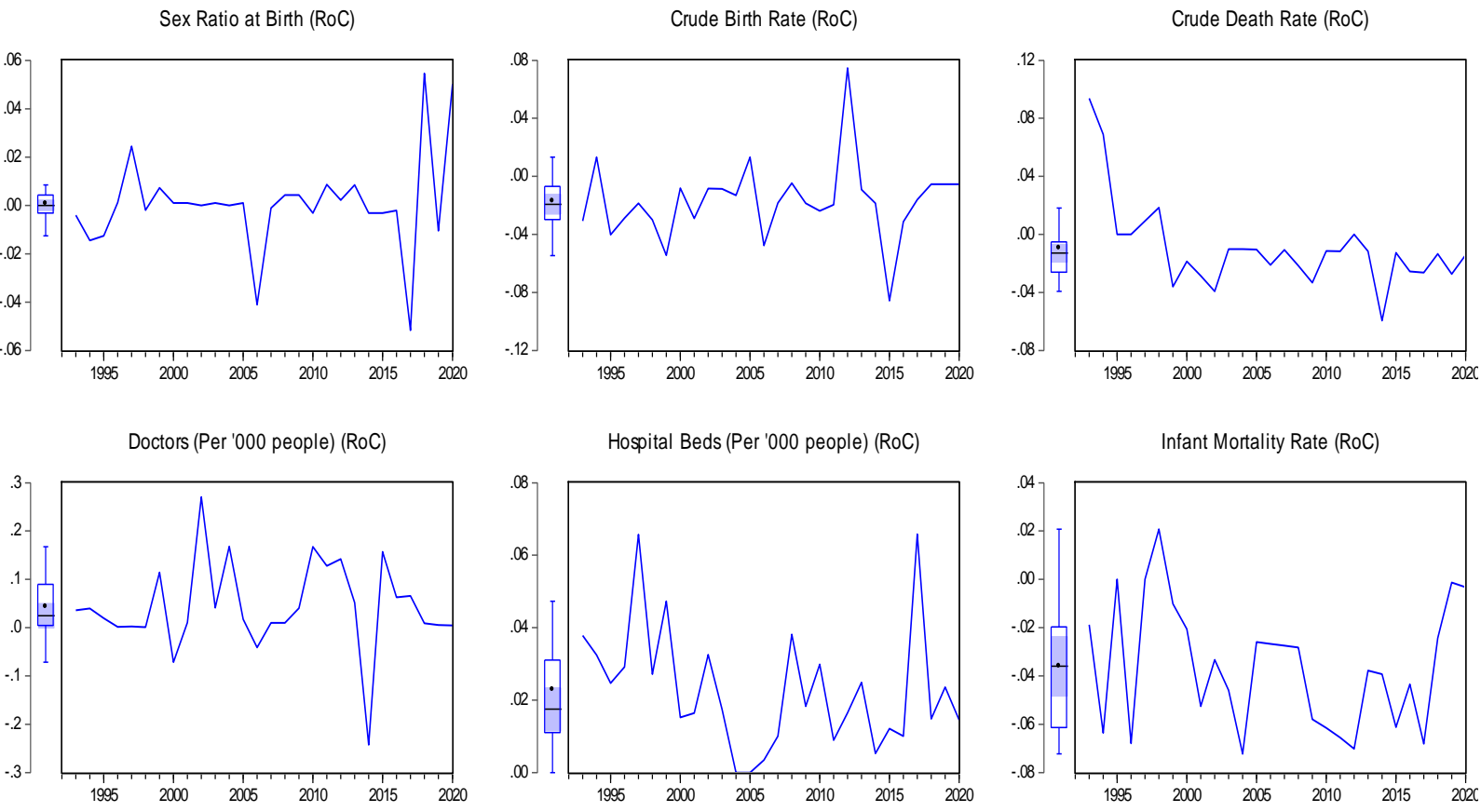

Life Expectancy at Birth (RoC)
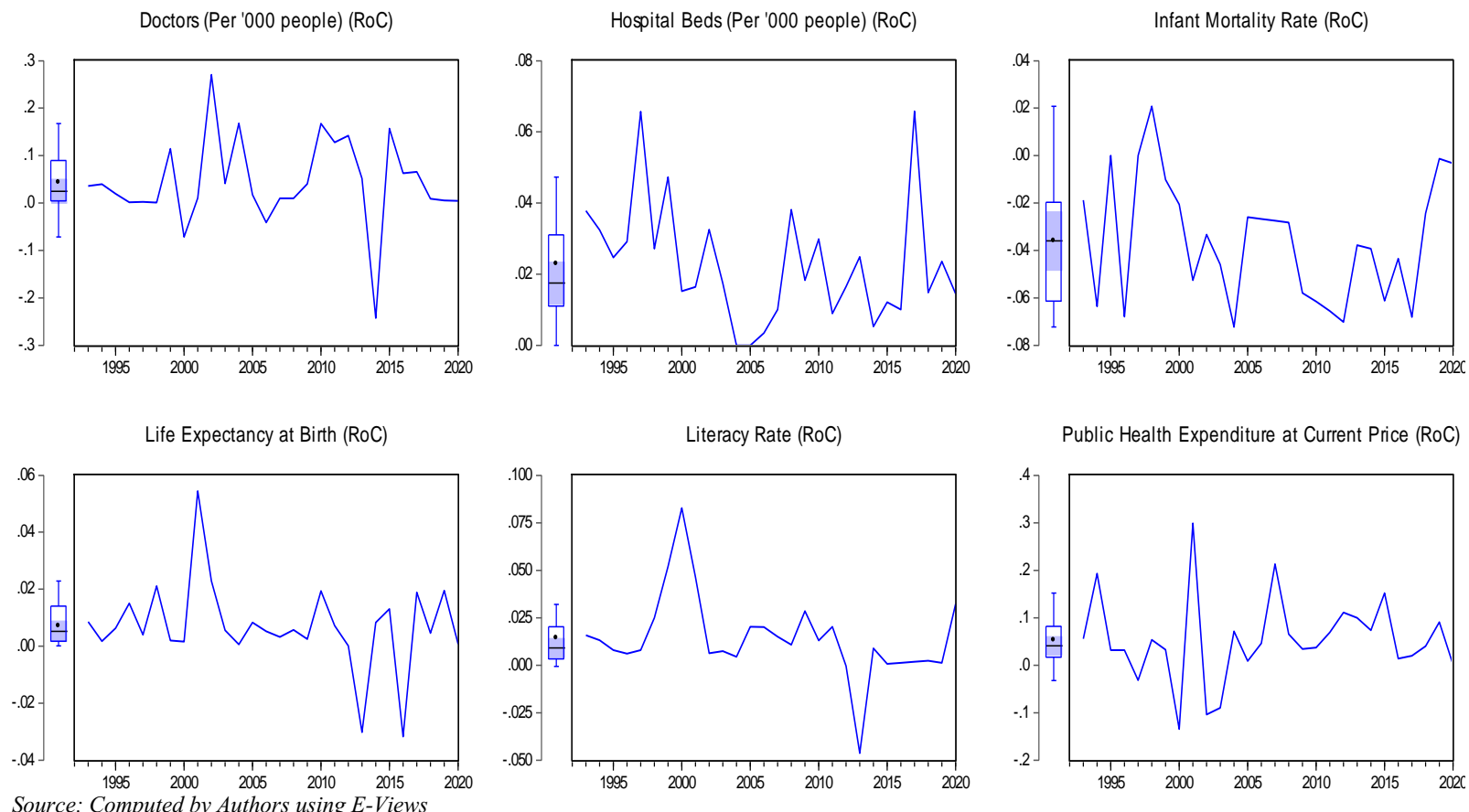

Figure-11 represents the trend line of the variables regarding the growth rate. The CDR decreases over the period from 1992 to 2020. Similarly, the CBR also decreases over the period of the study. This indicates a little bit better health infrastructure in Odisha. Moreover, the LEB increases during the study period and the literacy rate also increase during the same period. IMR decreases over the period and the hospital beds (Per '000 people) is showing the increasing in trend but form 2002 to 2005 it is constant. After it is again increased. Sex Ratio at Birth is showing the negative growth for the first three-four years, but after 1996 it is in increasing in trend up to 2005. Again increasing up to 2016 followed by negative growth with again positive growth. In the case of Doctors (Per '000 people) which is in constant

growth up to 2000, after this again it is in positive growth with fluctuation rate.

\section{FINDINGS AND SUGGESTIONS}

Cuttack and Ganjam are the only states which stand top in all respects like public health care expenditure, Availability and expenditure of Government health services and also exemplary health status as well. It is found that Jharsuguda, Gajapati, Malkangiri and Phulabani are lagging behind Ganjam, Cuttack, Khurda, and Sambalpur in their all mortality indicators, especially in child and reproductive healthcare. This may be due to a lack of necessary health infrastructure. In this regard, four suggestions can be made. Firstly the infrastructure whatever is there need to be distributed properly and executed with the 


\section{SJIF Impact Factor 2021: 8.013| ISI I.F.Value:1.241| Journal DOI: 10.36713/epra2016 ISSN: 2455-7838(Online) EPRA International Journal of Research and Development (IJRD) Volume: 6 | Issue: 4 | April 2021

necessary plan among all districts. The second is regarding a vacant post in the health sector which needs to be filled as soon as possible in a war footing manner. The next one is based on resolving the infrastructure shortfalls which should be resolved as per the population norms. The last one is regarding the opening of new medical centres and colleges which are very much required for any districts should be opened quickly with proper medical equipment.

It is said that prevention is better than cure that is we have to have proper infrastructure regarding any sector so that in future during an emergency we would not have any problems. So the government should focus on enhancing the health infrastructure. Moreover, there should be a proper executive committee regarding this matter so that delay should not be there.

\section{CONCLUSION}

It has been seen that with poor health care infrastructure, and poor status of health, Odisha is one of the long-way to meet the desired level of development. It is well understood that public health care systems. Which has a nation-wide network of delivering health and family welfare related services has a crucial role to achieve that desired level of development. However, the accessibility to the utilization of public health care across the whole comer of the state in Odisha is very poor. Health Service is a vital public property and a basic human right. So, all citizens should have an equal right to get better health facilities from the government. The government of Odisha has to play a key role in the up-gradation of the health facilities in the state for meeting urgent social need. In absence of that, the inhabitants of the state will be unable to face global competition in the race of progress. The peculiar nature of the health care market also necessitates the extensive involvement of the government in the health sector. The private participation in the health sector of Odisha is very insignificant; it can be stated as almost nil. Due to the limited health infrastructure facilities and nonsystematic distributions of these facilities make disparities in the different parts of the state. The remote vulnerable poor inhabitants are still out of modem health service facilities, which make them deprived of receiving equal health facilities in the rest part of the world and it results in low life expectancy at birth in the state. The failure of this public health delivery system is an outcome of the poor accountability of the services and concrete work relationships within the institutional framework. There is a large shortfall both in physical infrastructure and medical personnel, though minimal norms were prescribed earlier by the central government. Despite all these shortcomings, the Ministries of Health and Family Welfare of the Government of Odisha should continue to play their leadership role in health development and should advocate for the importance of investing in health and protecting the social values of equity, solidarity and fairness. The right efforts must be paid to health services of the state as the core area of social needs for the interest of comprehensive socio-economic development.

The health care system has developed and even improved over some time but inter and intra-state disparity between the states and among the districts tend to persist. By examining the overall scenario of the health sector, one can understand that it is difficult to achieve the goals of improving the health status of the population. India is facing a lot of challenges to prevent non-communicable diseases and communicable diseases. People of Odisha suffer from multiple diseases as the death rate in Odisha is the highest (8.5 per 1000 population) compared to other states. The health status in Malkangiri, Kandhamal, Koraput, Gajapati and Nabarangapur, found to be the worst. The government of Odisha should increase their health expenditure for a better supply of clean drinking water, sanitation, and build health infrastructure to improve the health condition of the people living in the remote areas of Odisha. It is disheartening to note that the investment in health care in rural areas of Odisha has declined over time and the expenditure on urban health care has increased. It seems that the government is giving more priority to the health sector of the urban area. Despite improving the resource allocation in an urban area there is an acute shortage of beds, doctors and nurses in government hospitals.

\section{REFERENCES}

1. Goli, S. (2012). Rural-Urban Divide. (October), 5255.

2. WHO (1946). The preamble to the Constitution of WHO as adopted by the International Health Conference, New York, 19 June - 22 July 1946.

3. Jana, N. C. \& Ghosh, P. K. (2015). Spatial and Social Disparities in Educational Status: A Case of Mayurbhan District in Odisha. India, International Journal of Current Research, 7(02):1310-1311.

4. Jalandhar, $\boldsymbol{P}$. \& Arokiasamy, P. (2006). High Infant and Child Mortality Rates in Orissa: an assessment of major reasons, International Institute for Population Science (IIPS), 1(1):187-200. 
SJIF Impact Factor 2021: 8.013| ISI I.F.Value:1.241| Journal DOI: 10.36713/epra2016 ISSN: 2455-7838(Online) EPRA International Journal of Research and Development (IJRD) Volume: 6 | Issue: 4 | April 2021

5. Patra, S. K., Annam, L. \& Ramadass, M. (2013).

National Rural Health Mission (NRHM) \& Health

Status of Odisha: An Economic Analysis. Health and Medical Care Services: Claims on National Resources, 1(14):305-315.

6. Barker A. R. \& Li L. (2020). The cumulative impact of health insurance on health status, Health Services Research, $0(0): 1-8$.

7. Mishra, P. \& Agarwal, A. (2017). Public Health in India: Gaps in Intent, Policy, and Practice. The Hindu center for politics and public policy, 1(7):1-30.

8. Patra, S. K., Annam, L. \& Ramadass, M. (2013). National Rural Health Mission (NRHM) \& Health Status of Odisha: An Economic Analysis. Indian Journal of Research, 13(4):44-47. https://doi.org/10.15373/22501991/may2014/15

9. Tekhre, Y.L., Tiwari, V.K. \& Khan, A.M. (2004). 'NGO-government' partnership for promoting primary health services: A feasibility analysis in Arunachal Pradesh. JOUR, 27(1):266-283. 